\title{
THE ELECTRONIZATION OF PROCUREMENT IN RUSSIA: THE IMPLEMENTATION RESULTS AND BARRIERS TO DEVELOPMENT
}

\author{
Olga N. Krasnova \\ Volgograd State University, Volgograd, Russian Federation
}

Introduction: the level of digitalization of the Russian economy achieved so far contributes to the formation of a digital platform for the public administration, whose further improvement will undoubtedly accelerate and simplify the interaction of the state with business. In recent years, the procurement sector has also been reformed in this direction: its electronization has been carried out, whose important stage has been the creation of a Unified Information System. The relevance of studying the results of these reforms lies in the need to identify the barriers to the development of electronic procurement, whose transformation into digitalization will certainly contribute to improving the efficiency of Russia's economic development. The purpose of the study is to assess the effectiveness of the electronic procurement system in Russia and to identify the factors hindering its development to develop proposals for its improvement. Methods: the methodological framework for the study is statistical and theoretical analysis, synthesis, comparison. Results: the paper presents the assessment results of the effectiveness of the electronic procurement system in Russia, its role in the country's economy, as well as the factors hindering its development. In the course of the analysis, the main characteristic features of the modern procurement system are highlighted; the relative savings in procurement are investigated. Conclusions: among the key shortcomings, the instability of the legislation in procurement and the wrong orientation of efforts to improve the functioning of the Russian procurement system are identified. The results obtained can serve as a basis for the development of proposals for its further development.

Key words: procurement system, electronization, digitalization, unified information system, legislation, reform.

Citation. Krasnova O.N. The Electronization of Procurement in Russia: The Implementation Results and Barriers to Development. Legal Concept = Pravovaya paradigma, 2021, vol. 20, no. 4, pp. 58-62. (in Russian). DOI: https://doi.org/10.15688/lc.jvolsu.2021.4.7

УДК 347.71

ББК 67.404 .213
Дата поступления статьи: 30.05.2021

Дата принятия статьи: 10.09.2021

\section{ЭЛЕКТРОНИЗАЦИЯ ЗАКУПОК В РОССИИ: РЕЗУЛЬТАТЫ ВНЕДРЕНИЯ И БАРЬЕРЫ В РАЗВИТИИ}

\author{
Ольга Николаевна Краснова \\ Волгоградский государственный университет, г. Волгоград, Российская Федерация
}

Введение: достигнутый к настоящему времени уровень цифровизации экономики России способствует формированию цифровой платформы государственного управления, дальнейшее совершенствование которого, несомненно, ускорит и упростит взаимодействие государства с бизнесом. В последние годы в данном направлении реформируется и сфера закупок: происходит ее электронизация, важным этапом которой стало создание Единой информационной системы. Актуальность изучения результатов данных реформ заключается в необходимости выявления барьеров в развитии электронизации сферы закупок, трансформация которой в цифровизацию, безусловно, будет способствовать повышению эффективности экономического развития России. Целью исследования является оценка результативности электронизации системы закупок в России и выявление факторов, сдерживающих ее развитие, в целях разработки предложений по ее совершенствованию. Методы: методологическую основу данного исследования составляют статистический и теоретический анализ, синтез, сравнение. Результаты: в статье представлены результаты оценки 
эффективности электронизации системы закупок в России, ее роль для экономики страны, а также факторы, сдерживающие ее развитие. В ходе анализа охарактеризованы основные черты современной системы закупок, исследована относительная экономия при их осуществлении. Выводы: среди ключевых недостатков выделены нестабильность законодательства в сфере закупок и неправильная направленность усилий по совершенствованию функционирования российской системы закупок. Полученные результаты могут служить основой для разработки предложений по ее дальнейшему развитию.

Ключевые слова: система закупок, электронизация, цифровизация, единая информационная система, законодательство, реформирование.

Цитирование. Краснова О. Н. Электронизация закупок в России: результаты внедрения и барьеры в развитии // Legal Concept=Правовая парадигма. - 2021. - T. 20, №4. - C. 58-62. - DOI: https://doi.org/10.15688/lc.jvolsu.2021.4.7

\section{Введение}

В сектор закупок вовлекаются внушительные объемы бюджетных средств. Так, в России за 2019 г. из бюджетов всех уровней вложены 31,6 трлн руб., что составляет почти $29 \%$ ВВП: из них в рамках Федерального закона № 44-Ф3 «О контрактной системе в сфере закупок товаров, работ, услуг для обеспечения государственных и муниципальных нужд» $-8,1$ трлн руб. [6]; в рамках Федерального закона № 223-Ф3 «О закупках товаров, работ, услуг отдельными видами юридических лиц» $-23,5$ трлн руб. [5]. Для сравнения в странах Организации экономического сотрудничества и развития эти вложения составляют около 12 \% ВВП, в Евросоюзе - 18-20\% ВВП. Данные показатели явно свидетельствуют о значимой роли системы закупок для экономики страны.

31 декабря 2017 г. был подписан Федеральный закон № 504-Ф3 «Об изменении контрактной системы» [7], предусматривающий новые электронные способы закупок. С 2019 г. электронные конкурентные процедуры стали обязательными для всех заказчиков.

\section{Черты современной системы закупок в России}

Результаты исследования позволили выделить черты, характерные для действующей в России во время электронизации системы закупок.

Во-первых, электронный аукцион стал преобладающим способом закупки, начиная с 2014 года. За период 2014-2019 гг. в России доля электронного аукциона в структуре закупок постоянно увеличивалась и в целом выросла с $56,8 \%$ до $76,9 \%$.
Во-вторых, в системе преобладают неконкурентные закупки. Так, в рамках № 44-Ф3 на контракты с единственным поставщиком и несостоявшиеся закупки приходится $76 \%$ всех закупок, а в рамках № 223-Ф3 - на закупки у единственного поставщика и закупки прочими способами - 86,1\%.

Уровень конкуренции практически не изменился. В рамках № 44-Ф3 он составляет порядка трех заявок на лот: среднее число заявок на один лот в 2014 г. составляло 2,88 , а в 2019 г. - 3,12. В корпоративном секторе уровень конкуренции с 2014 г. не превысил двух заявок на один лот [2].

Несмотря на запуск нескольких электронных площадок, в современной системе закупок все еще присутствует недобросовестная конкуренция. Так, количество нарушений в сфере закупок в рамках № 44-ФЗ выросло с 56905 в 2015 г. до 91886 в 2019 г., то есть на $61,5 \%$, а в рамках № 223-Ф3 - с 5787 до 20338 за этот же период, то есть в 3,5 раза.

В-третьих, участники закупок слабо доверяют системе государственных и корпоративных закупок. Об этом свидетельствует ежегодное сокращение числа поставщиков, которое в 2019 г. составило $25 \%$, а сравнительно с показателем 2014 г. - 27 \% [2]. Например, за 2019 г. количество участников закупок, принявших участие в корпоративных закупках, снизилось на 43,4 \%. Такая тенденция недоверия говорит о снижении в рассматриваемом периоде привлекательности в России системы закупок.

\section{Факторы, сдерживающие повышение} эффективности системы закупок в России

Несмотря на электронизацию российской системы закупок, она все еще не способствует 
экономическому росту страны в должной мере. Относительная экономия бюджетных средств при осуществлении закупок значительно снизилась: с 10,49 \% в 2016 г. до 5,5\% в 2019 году. Экономия по итогам осуществления закупок конкурентными способами в 2019 г. составила 5,13 \% (см. рисунок).

Какие же факторы сдерживают повышение эффективности системы закупок в России?

Одним из них является сосредоточение усилий по развитию системы закупок на процедурах осуществления закупок, а не, как представляется более рациональным, на достижении их результативности и обеспечении необходимого качества товаров, услуг, работ [3, с. $134 ; 4$, с. 140]. Серьезным сдерживающим фактором является нестабильность и сложность законодательства. Так, только за 2019 г. № 44-Ф3 корректировался восемь раз, а для его совершенствования принято 55 нормативно-правовых актов. Постоянные изменения законодательства о закупках обременяют контрактную систему для заказчиков и делают непривлекательной для поставщиков. Рамочный характер № 223-Ф3 приводит к тому, что на практике заказчики используют в основном прочие способы закупки с элементами, которые существенно ограничивают конкуренцию. Он не регламентирует достаточно детально закупочную деятельность.

Единая информационная система в сфере закупок совершенствуется и развивается, однако ее функции, включая переход к структурированной электронной документации, все еще не реализованы в полной мере. Следовательно, в ближайшей перспективе необходимо дальнейшее ее реформирование.

\section{Выводы}

Несмотря на электронизацию российской системы закупок, она все еще не способствует экономическому росту страны в должной мере. Ее характерными чертами остаются неизменно низкий уровень конкуренции, недоверие участников закупочной деятельности, множественные нарушения в сфере закупок. Единую информационную систему невозможно использовать в настоящее время как надежную базу для цифровизации закупочной деятельности.

Сдерживающими факторами развития российской системы закупок являются:

- нестабильность и сложность законодательства;

- концентрация усилий на процедурах закупок, а не на их результативности и обеспечении качества товаров, услуг и работ.

Устранение данных недостатков будет способствовать дальнейшему эффективному развитию электронизации российской системы закупок и последующей цифровизации закупочной деятельности. Это, в свою очередь, благоприятно отразится на экономическом развитии страны в целом.

\section{СПИСОК ЛИТЕРАТУРЫ}

1. Единая информационная система в сфере закупок. - Электрон. текстовые дан. - Режим доступа: https://zakupki.gov.ru/epz/main/ public/ home.html (дата обращения: 30.04.2021). - Загл. с экрана.

2. Каульбарс, А. А. Отчет о результатах экспертно-аналитического мероприятия «Мониторинг

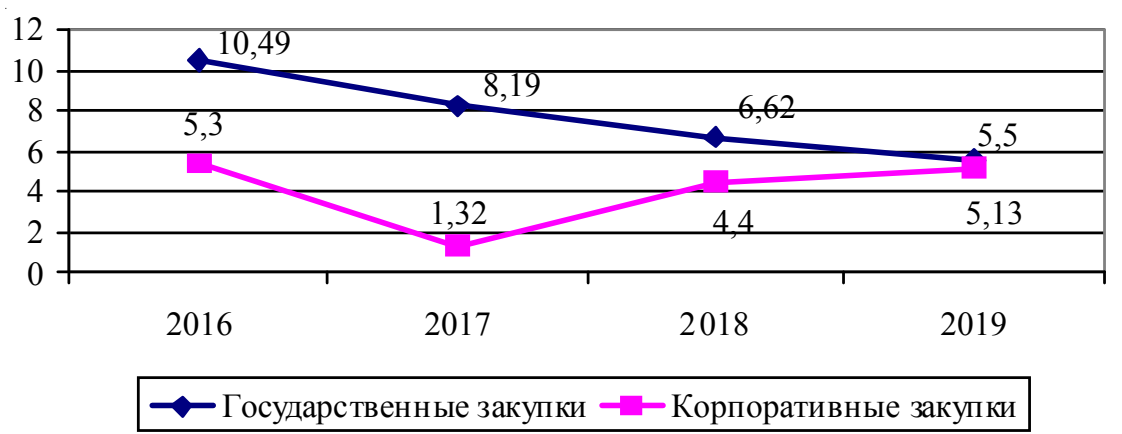

Рисунок. Относительная экономия при осуществлении государственных и корпоративных закупок за 2016-2019 гг., \%

Примечание. Составлено автором по: [1]. 
развития системы государственных и корпоративных закупок в Российской Федерации за 2019 год», 2020 / А. А. Каульбарс. - Электрон. текстовые дан. Режим доступа: https://ach.gov.ru/upload/iblock/fea/ fea86920fc7f4c8b39262ce74beb32d8.pdf (дата обращения: 29.04.2021). - Загл. с экрана.

3. Матыцин, Д. Е. Обеспечение исполнения государственных и муниципальных контрактов: банковские гарантии и цифровые технологии / Д. Е. Матыцин, И. В. Балтутите // Евразийский юридический журнал. - 2020. -№ 11 (150). - С. 133-136.

4. Матыцин, Д. Е. Цифровые технологии реализации гражданско-правовых сделок: договор репо на инвестиционные активы рынка ценных бумаг / Д. Е. Матыцин // Право и практика. - 2020. № 2. - С. 136-140.

5. Федеральный закон от 18.07.2011 № 223-Ф3 «О закупках товаров, работ, услуг отдельными видами юридических лиц». - Электрон. текстовые дан. - Режим доступа: https://www.consultant.ru/ document/cons_doc_LAW_116964 (дата обращения: 24.04.2021). - Загл. с экрана.

6. Федеральный закон от 05.04.2013 № 44-Ф3 «О контрактной системе в сфере закупок товаров, работ, услуг для обеспечения государственных и муниципальных нужд». - Электрон. текстовые дан. Режим доступа: https://www.consultant.ru/document/ cons_doc_LAW_144624/ (дата обращения: 24.04.2021). - Загл. с экрана.

7. Федеральный закон от 31.12.2017 № 504-Ф3 «О внесении изменений в Федеральный закон “О контрактной системе в сфере закупок товаров, работ, услуг для обеспечения государственных и муниципальных нужд”». - Электрон. текстовые дан. - Режим доступа: https://www.consultant.ru/ document/cons_doc_LAW_286777/ (дата обращения: 27.04.2021). - Загл. с экрана.

\section{REFERENCES}

1. Edinaia informatsionnaia sistema $v$ sfere zakupok [Unified Information System in the Field of Procurement]. URL: https://zakupki.gov.ru/epz/main/ public/home.html (accessed 30 April 2021).

2. Kaulbars A.A. Otchet o rezultatakh ekspertnoanaliticheskogo meropriiatiia «Monitoring razvitiia sistemy gosudarstvennykh i korporativnykh zakupok v Rossiiskoi Federatsii za 2019 god», 2020 [Report on the Results of the Expert-Analytical Event "Monitoring the Development of the System of State and Corporate Procurement in the Russian Federation for 2019']. URL: https://ach.gov.ru/upload/ iblock/fea/fea86920fc7f4c8-b39262ce74beb32d8.pdf (accessed 29 April 2021).

3. Matycin D.E., Baltutite I.V. Obespechenie ispolneniya gosudarstvennyh i municipal'nyh kontraktov: bankovskie garantii i cifrovye tekhnologii [Ensuring the Execution of State and Municipal Contracts: Bank Guarantees and Digital Technologies]. Evrazijskij yuridicheskij zhurnal [Eurasian Legal Journal], 2020, no. 11 (150), pp. 133-136.

4. Matycin D.E. Cifrovye tekhnologii realizacii grazhdansko-pravovyh sdelok: dogovor repo na investicionnye aktivy rynka cennyh bumag [Digital Technologies for the Implementation of Civil Law Transactions: A Repo Agreement for Investment Assets of the Securities Market]. Pravo i praktika [Law and Practice], 2020, no. 2, pp. 136-140.

5. Federalnyi zakon ot 18.07.2011 № 223-FZ "O zakupkakh tovarov, rabot, uslug otdelnymi vidami iuridicheskikh lits» [Federal Law No. 223-FZ Dated July 18, 2011 "On Procurement of Goods, Works, and Services by Certain Types of Legal Entities"]. URL: https://www.consultant.ru/document/cons doc_LAW_116964 (accessed 24 April 2021).

6. Federalnyi zakon ot 05.04.2013 № 44-FZ "O kontraktnoi sisteme $v$ sfere zakupok tovarov, rabot, uslug dlia obespecheniia gosudarstvennykh i munitsipalnykh nuzhd» [Federal Law No. 44-FZ Dated April 5, 2013 “On the Contract System in the field of Procurement of Goods, Works, and Services for State and Municipal Needs"]. URL: https:// WWw.consultant.ru/document/cons_doc_ LAW_144624(accessed 24 April 2021).

7. Federalnyi zakon ot 31.12.2017 № 504-FZ "O vnesenii izmenenii $v$ Federalnyi zakon "O kontraktnoi sisteme $v$ sfere zakupok tovarov, rabot, uslug dlia obespecheniia gosudarstvennykh $i$ munitsipalnykh nuzhd"» [Federal Law No. 504-FZ Dated December 31, 2017 "On Amendments to the Federal Law 'On the Contract System in the Field of Procurement of Goods, Works, and Services for State and Municipal Needs" "]. URL: https:// www.consultant.ru/document/cons_doc_LAW_286777 (accessed 27 April 2021). 


\section{Information About the Author}

Olga N. Krasnova, Head of the Procurement Department, Master Student, Department of Constitutional and Municipal Law, Volgograd State University, Prosp. Universitetsky, 100, 400062 Volgograd, Russian Federation, krasnova7@mail.ru, https://orcid.org/0000-0002-8259-8493

\section{Информация об авторе}

Ольга Николаевна Краснова, начальник отдела закупок, магистрант кафедры конституционного и муниципального права, Волгоградский государственный университет, просп. Университетский, 100, 400062 г. Волгоград, Российская Федерация, krasnova7@mail.ru, https://orcid.org/0000-0002-8259-8493 